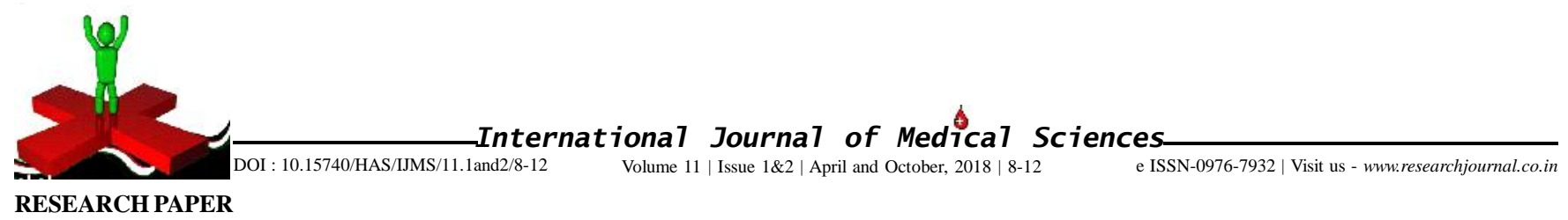

\title{
An Apple a Day Keeps Parkinsonism Away
}

\section{Milind Parle and Pankaj Rakha}

See end of the paper for authors' affiliation

Correspondence to :

\section{Milind Parle}

Guru Jambheshwar University of Science and Technology, Hisar (Haryana) India Email: mparle@rediffmail. com

\section{KEY WORDS :}

Abnormal posture, Hypokinesia, Parkinsonism, Apple, Rigidity
ABSTRACT : Parkinson's disease is a progressive neurological disorder characterized by tremors, rigidity, shuffling gait and hypokinesia. Deficiency of Dopamine in substantia nigra pars compacta is the main cause of the disease. Bromocriptine can be used as an alternate to levodopa because this drug is a direct agonist of striatal dopamine receptors. Therefore, in the present study Bromocriptine served as a standard drug. The main phytoconstituents of Apple fruit are vitamin $\mathrm{B}_{3}$, Vitamin $\mathrm{B}_{6}$, flavanoids and phenolic compounds such as polyphenol oxidase. Niacin is also reported to improve cognitive as well as motor function by stimulating the production of neurotransmitters. Therefore, anti-parkinsonian potential of Apple juice was investigated in the present study. Apple juice $(0.5 \mathrm{ml}$ and $1 \mathrm{ml} / 100 \mathrm{~g}$ p.o.) reduced the severity of tremors evoked by oxotremorine $(0.5 \mathrm{mg} / \mathrm{kg}$, i. p.). Apple juice diminished rigidity induced by Reserpine and restored the mobility impaired by Reserpine ( $5 \mathrm{mg}$ / $\mathrm{kg}$, i. p.) in rodents. Apple juice appears to produce its anti-parkinsonian activity mediated via enhanced dopamine and nor-epinephrine synthesis, increased cereberal blood flow through stimulation of NO production, antioxidant activity and neuroprotective action.

How to cite this paper : Parle, Milind and Rakha, Pankaj (2018). An Apple a Day Keeps Parkinsonism Away. Internat. J. Med. Sci., 11(1\&2) : 8-12, DOI: 10.15740/HAS/IJMS/11.1and2/8-12.Copyright@ 2018: Hind Agri-Horticultural Society.
Paper History : 